\title{
Mitral valve hemodynamics after repair of acute posterior leaflet prolapse: Quadrangular resection versus triangular resection versus neochordoplasty
}

\author{
Muralidhar Padala, MS, ${ }^{a}$ Scott N. Powell, BS, ${ }^{\text {a }}$ Laura R. Croft, BS, ${ }^{\text {a }}$ Vinod H. Thourani, MD, \\ Ajit P. Yoganathan, $\mathrm{PhD},{ }^{\mathrm{a}}$ and David H. Adams, $\mathrm{MD}^{\mathrm{c}}$
}

\begin{abstract}
Objective: Leaflet prolapse resulting from acute chordal rupture is one presentation of fibroelastic deficiency that is associated with minimal leaflet changes in the prolapsing segment. Minimizing resection and preserving leaflet tissue may be an optimal surgical strategy. We examined the importance of the leaflet preservation concept by comparing resective and nonresective surgical procedures in practice today.
\end{abstract}

\begin{abstract}
Methods: Eight porcine mitral valves were evaluated in an in vitro heart simulator before surgical manipulation. Mitral regurgitation was created in these valves by transecting the posterior marginal chordae resulting in severe $\mathrm{P} 2$ prolapse. After confirmation of mitral regurgiation via regurgitant flow measurement (mL/beat), regurgitation was corrected by three repairs: neochordoplasty with polytetrafluoroethylene sutures (Gore-Tex; W. L. Gore \& Associates, Inc, Flagstaff, Ariz), triangular resection, and quadrangular resection with annular compression. Postrepair valve hemodynamics were quantified under pulsatile conditions of $120 \mathrm{~mm} \mathrm{Hg}$ peak transmitral pressure and $5 \mathrm{~L} / \mathrm{min}$ cardiac output at 70 beats/min. Furthermore, hemodynamic, geometric, and echocardiographic indices were measured.
\end{abstract}

Results: Transecting the marginal chordae resulted in severe P2 prolapse and significant mitral regurgiation (19.3 $\pm 4.3 \mathrm{~mL} /$ beat). Regurgitant volume was significantly reduced after any of the three surgical approaches (quadrangular, $4.38 \pm 1.6 \mathrm{~mL} /$ beat; triangular, $2.56 \pm 1.0 \mathrm{~mL} /$ beat; neochordal, $2.86 \pm 1.24 \mathrm{~mL} /$ beat). In comparison with the baseline normal valves, leaflet coaptation length and posterior leaflet mobility were significantly reduced in the quadrangular resection group, whereas they were partially restored in the triangular resection and fully preserved in the neochordoplasty group.

Conclusions: Although the three repair procedures are hemodynamically comparable, valve function and leaflet kinematics were significantly better after a nonresection or limited resective correction of leaflet prolapse in this experimental model of acute chordal rupture with otherwise normal leaflet geometry.

Surgical strategies addressing mitral regurgitation resulting from chordal rupture often involve partial leaflet resection with or without annular plication and annuloplasty. In the chronic setting, leaflet distension and myxoid changes may occur in the prolapsing segment and various resective techniques have been described with excellent results. ${ }^{1}$ However, in patients with leaflet prolapse resulting from acute chordal rupture, distension of leaflets is minimal early in the course of mitral valve regurgitation, ${ }^{2,3}$ and leaflet resec-

\footnotetext{
From the Wallace H. Coulter Department of Biomedical Engineering, Georgia Institute of Technology, ${ }^{\text {a }}$ the Division of Cardiothoracic Surgery, Emory University School of Medicine, ${ }^{b}$ Atlanta, Ga; and the Department of Cardiothoracic Surgery, ${ }^{c}$ Mt Sinai School of Medicine, New York, NY.

Read at the Eighty-eighth Annual Meeting of The American Association for Thoracic Surgery, San Diego, Calif, May 10-14, 2008.

Received for publication May 13, 2008; revisions received Dec 9, 2008; accepted for publication Jan 13, 2009.

Address for reprints: Ajit P. Yoganathan, PhD, The Wallace H. Coulter Distinguished Faculty Chair in Biomedical Engineering and Regents Professor, Associate Chair for Research, Wallace H. Coulter School of Biomedical Engineering, Georgia Institute of Technology and Emory University, Room 2119 U. A. Whitaker Building, 313 Ferst Dr, Atlanta, GA 30332-0535 (E-mail: ajit.yoganathan@bme.gatech.edu). J Thorac Cardiovasc Surg 2009;138:309-15

$0022-5223 / \$ 36.00$

Copyright (c) 2009 by The American Association for Thoracic Surgery

doi:10.1016/j.jtcvs.2009.01.031
}

tion may not be as effective a strategy. Under such acute conditions, resective techniques may limit residual leaflet mobility and the leaflet surface available for opposing leaflet coaptation. We used an in vitro model of acute chordal rupture to compare mitral valve function and hemodynamics after valve repair with common repair techniques including neochordoplasty (no resection), triangular resection, and quadrangular resection with annular plication.

\section{RESEARCH DESIGN AND METHODS Specimen Selection}

Porcine hearts were obtained from a local abattoir and transported to the laboratory in ice cold phosphate-buffered saline solution. Eight hearts ( $\mathrm{n}=$ 8) with mitral valves of identical sizes (size 30 annuloplasty ring sizers; Edwards LifeSciences, Irvine, Calif) were identified for use in this study. Valves of the same annular size, anterior and posterior leaflet areas, and heights were selected for this study. Mitral valves with intact annular and subvalvular structures (including the papillary muscles) were extracted from these hearts and stored in cold saline for later use. A 1-cm section of atrial tissue above the mitral annulus was left uncut, and this tissue was used to suture the valve onto a silicone annulus to mount into the left heart simulator.

\section{In Vitro Left Heart Simulator}

The in vitro experimental left heart simulator used in this study is a wellestablished setup that was reported previously. ${ }^{4,5}$ In brief, the simulator (Figure 1, A) is a computer-controlled, pressure-driven, compressible 


\author{
Abbreviations and acronyms \\ $\alpha \quad=$ posterior excursion angle \\ $\beta \quad=$ anterior excursion angle \\ $\Delta_{\mathrm{a}}=$ distance from coaptation to \\ anterior annulus \\ $\Delta_{\mathrm{p}} \quad=$ distance from coaptation to \\ posterior annulus \\ ePTFE $=$ expanded polytetrafluoroethylene
}

bladder system that can generate the physiologic pulsatile flow and pressure flow conditions of the left heart. The simulator has a left atrium, a left ventricle, and a mitral annular plate sandwiched between them. The mitral annulus plate has a D-shaped ring made of silicone that is rigid and is covered in a water-proofing polyester (Darlexx; Darlington Fabrics Corp, Shawnut Mills, Mass). The mitral annulus was sutured onto the silicone ring with 3-0 silk sutures in a mattress fashion and the papillary muscles were mounted onto two adjustable-geared fixtures in the left ventricular chamber. After the valve was mounted, the simulator was filled with $0.9 \%$ saline solution ( $\mathrm{vol} / \mathrm{vol}$ ) and run at adult hemodynamic conditions of $120-\mathrm{mm} \mathrm{Hg}$ peak transmitral pressure and $5-\mathrm{L} / \mathrm{min}$ cardiac output at 70 beats/min (Figure 1, $B$ and $C$ ). The left ventricular, left atrial, and transmitral pressure curves were monitored and recorded with a differential pressure transducer (DP9-40; Validyne Engineering, Northridge, Calif), and the flow data were monitored with an electromagnetic flow probe (600; Braemar Inc, King, NC). The acquisition, signal conditioning, and analysis were performed with DAQCard 1200 (National Instruments, Austin, Tex) and a custom data processing program (DAQ-ANAL 2.0).

\section{Experimental Protocol}

Each mitral valve was studied under the experimental conditions in the order listed herein:

1. Control/baseline. The annulus was maintained at its normal size, and the papillary muscles were fixed in their normal positions, ie, with the papillary muscle tips perpendicular to the mitral annular plane and in the plane passing through leaflet coaptation, such that the commissural chordae from the same papillary muscle are parallel to each other. The valve was studied under adult hemodynamic conditions of $120-\mathrm{mm} \mathrm{Hg}$ peak transmitral pressure and $5-\mathrm{L} / \mathrm{min}$ cardiac output at 70 beats/min. The regurgitant volume and stroke volume were volumetrically measured, and leaflet coaptation length and indices that elucidate leaflet mobility were recorded with 2-dimensional echocardiograph (Figure 2, A).

2. Posterior leaflet prolapse. After acquisition of the baseline data, the two marginal chordae on the free edge of the posterior leaflet were transected, which resulted in severe segmental prolapse of the P2 cusp. The simulator was again run under the identical hemodynamic conditions described previously, and the hemodynamic and echocardiographic measurements were obtained. P2 prolapse was validated by reconstructing the 3-dimensional geometry of the mitral valve from the echocardiographic images and superimposed with only the reverse color Doppler data, showing the regurgitation jet as shown in Figure 2, B. The regurgitation and stroke volumes were also quantified with the flow probe.

3. Neochordoplasty. In this procedure, the transected marginal chordae tendineae were replaced with loops of 5-0 expanded polytetrafluoroethylene sutures (ePTFE; Gore-Tex, W. L. Gore \& Associates, Inc, Flagstaff, Ariz), ${ }^{6}$ as shown in Figure 3, A. The ventricular chamber was filled with saline to close the mitral valve, lengths of the neochordae were adjusted, and the neochordae were tied onto a Teflon pledget on the tip of the papillary muscle. The valve was then tested under pulsatile hemodynamic flow conditions as listed in the previous sections, and relevant hemodynamic and echocardiographic end points were measured.

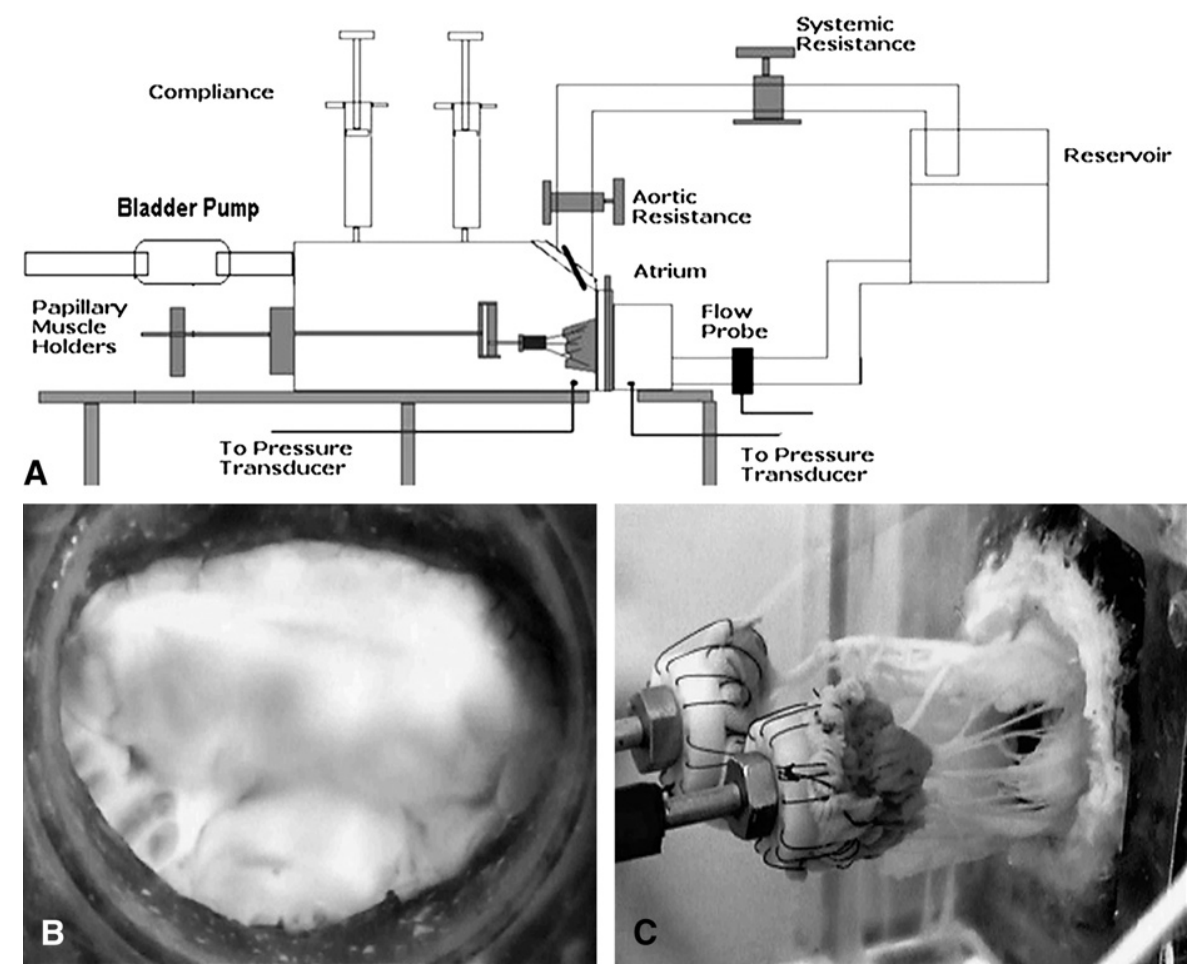

FIGURE 1. A, Schematic of the in vitro left heart simulator with a native porcine mitral valve. B, Atrial view of the mitral valve showing the anterior and the posterior leaflets. C, Ventricular view of the valve showing the chordae tendineae and the papillary muscles. 

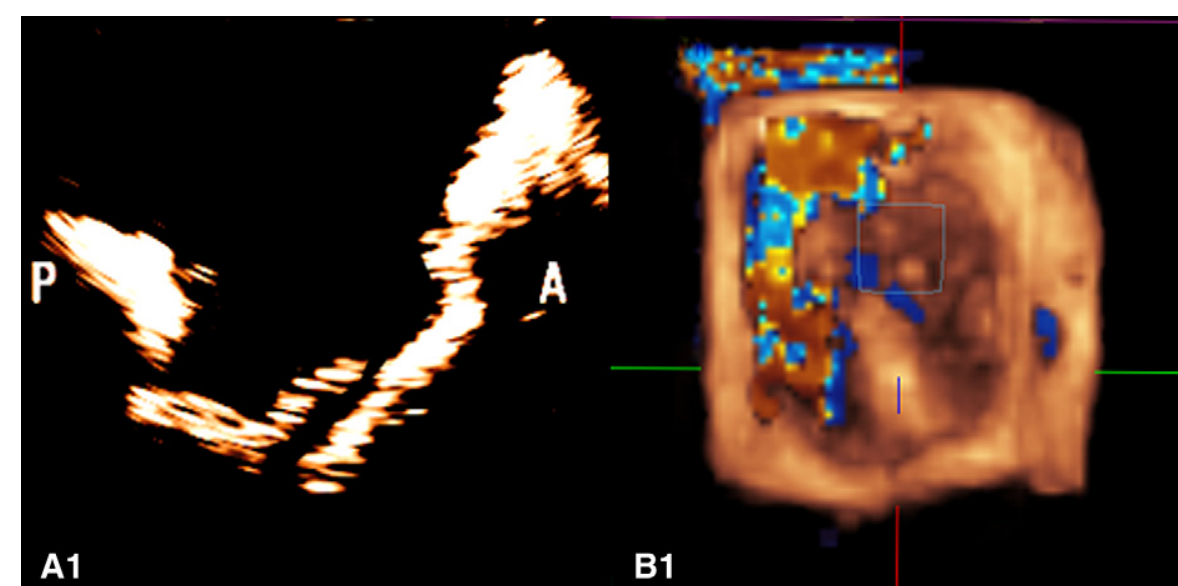

B1

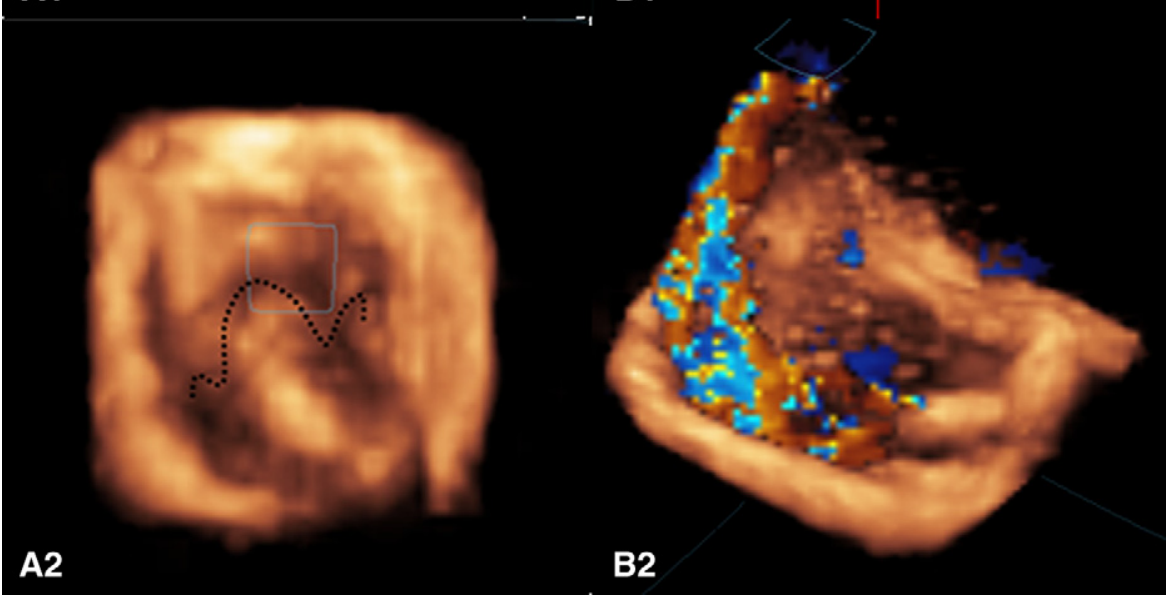

FIGURE 2. A, The top left image is a 2-dimensional echocardiograph that shows the prolapsing P2 scallop of the posterior leaflet resulting from chordal transection, and the bottom left image is a 3-dimensional reconstruction of the prolapsing leaflet as seen from the left atrium. The 3-dimensional reconstruction clearly shows the leaflet prolapse and the loss of leaflet coaptation. B, The 3-dimensional eccentric regurgitation jet recorded by 3-dimensional echocardiography from the top view and isometric views. A regurgitation jet directed toward the anterior annulus can be clearly seen with the posterior leaflet prolapse.

4. Limited triangular resection. After acquisition of the data in step 3, the neochordae were removed and a triangular resection was performed on the free edge of the P2 scallop (Figure 3,B). The total height of the posterior leaflet from the free edge to the annulus was measured, and a triangular segment that had a height of one third (total leaflet height) and a base width equal to the length between the two ruptured marginal chordae was resected as reported in an earlier study by Gazoni and associates. ${ }^{7}$ The posterior leaflet was reconstructed by carefully approximating the free edges of the triangular resection with interrupted 3-0 silk sutures (Ethicon Inc, Somerville, NJ), such that minimal tension was induced on the residual leaflet segments. After reconstruction of the leaflet, the valve was again tested under the pulsatile hemodynamic conditions that were previously used.

5. Quadrangular resection with annular compression. Quadrangular resection was performed on the same valve by resecting a rectangular section of the P2 segment and compressing the annulus at this region, ${ }^{8}$ as shown in Figure 3, C. The dimensions of the resected segment were chosen such that the breadth of the rectangle equaled the distance between the two ruptured marginal chordae and the length extended from the free edge to the mitral annulus. The section of the annulus in the resected region was then plicated and approximated with 3 or 4 compression sutures. The free edges after resection were carefully approximated with interrupted knots with 3-0 silk sutures in a similar fashion to that used in the triangular resection group. The valve was then tested under pulsatile hemodynamic conditions.

\section{Measurement Techniques and Data Acquisition}

Regurgitation volume. Regurgitant volume through the valve was calculated from the recorded transmitral flow curve. The flow curve was averaged over 15 cardiac cycles and the area under the negative part of the flow curve was integrated to obtain the net regurgitation volume.

Echocardiographic measurements. Three-dimensional echocardiographic measurements were obtained with a 3-dimensional matrixarray ultrasound sector transducer (X7 Matrix Probe; iE33 System, Philips Medical Systems, Andover, Mass) at $18 \mathrm{MHz}$. The transducer was adjusted to provide optimal imaging with the highest possible frame rate at a sampling depth of $12 \mathrm{~cm}$. An apical long-axis view cutting across both the leaflets anteroposteriorly at the midpoint of the major axis of the annulus was used for the measurements. Echocardiographic and color Doppler images were obtained to assess the forward and the leakage flow through the cleft and the coaptation regions. Peak systolic leaflet coaptation length, posterior leaflet angle, ${ }^{9}$ and distance of the coaptation plane from the posterior annulus were measured.

\section{Statistical Analysis}

All data are reported as mean \pm 1 standard deviation. The data were tested for normality by an Anderson-Darling test (MINITAB 15 software). Different experimental condition groups were compared with paired $t$ tests. 


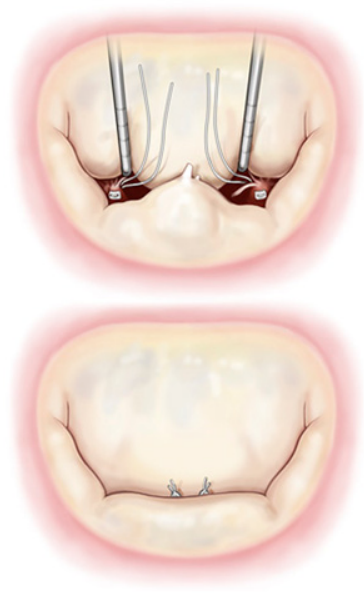

Neochordae

A

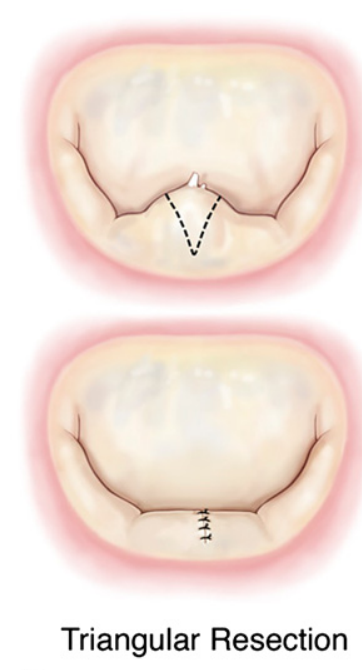

B

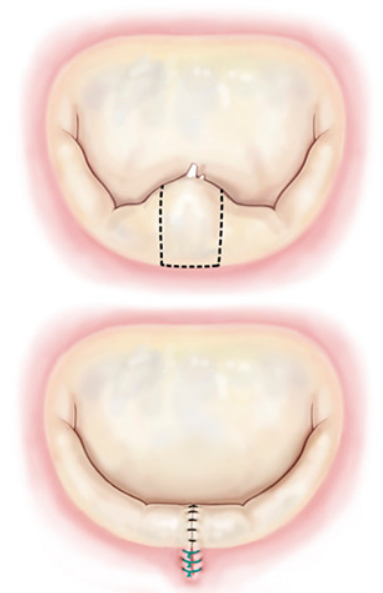

Quadrangular Resection

\section{$\mathrm{C}$}

FIGURE 3. A, Sequential steps to replace the ruptured posterior chordae tendineae with loops of 5-0 ePTFE sutures. B, Sequential steps to perform triangular resection and approximation of the resected region. C, Protocol to perform quadrangular resection and annular plication with a compression stitch.

\section{RESULTS}

\section{Mitral Regurgitation Volumes}

All the valves had good competence under control/baseline conditions with trivial regurgitation. Transecting the two posterior marginal chordae resulted in segmental P2 scallop prolapse causing severe mitral regurgitation (19.31 $\pm 4.3 \mathrm{~mL} /$ beat). The three repairs significantly reduced the regurgitation from the prolapse condition, to $2.8 \pm 1.2$ $\mathrm{mL} /$ beat $(P=.007)$ with neochordoplasty, $2.5 \pm 1.0 \mathrm{~mL} /$ beat $(P=.008)$ with limited triangular resection, and 4.3 $\pm 1.5 \mathrm{~mL} /$ beat $(P=.007)$ with quadrangular resection and annular compression (Figure $4, A$ ).

\section{Leaflet Coaptation Length}

Leaflet coaptation length was used as a measure of valve competence that was quantified under all the experimental conditions by 2-dimensional echocardiography. Under con- trol conditions, an average coaptation length of $11.4 \pm 1.4$ $\mathrm{mm}$ was measured, whereas under prolapse conditions there was no coaptation along the A2-P2. Neochordoplasty was the only repair that restored coaptation length to the control/baseline levels $(11.8 \pm 1.7 \mathrm{~mm} ; P=.2)$, whereas both limited triangular resection and quadrangular resection decreased the coaptation length significantly to $9.4 \pm 1.4$ $\mathrm{mm}(P=.01)$ and $7.2 \pm 0.8 \mathrm{~mm}(P=.0001)$, respectively (Figure 4, B).

\section{Postrepair Leaflet Mobility and Kinematics}

Posterior leaflet mobility after each surgical repair was assessed by simple echocardiographic measurements: (1) perpendicular distances from the leaflet coaptation zone to the posterior $\left(\Delta_{\mathrm{p}}\right)$ and anterior $\left(\Delta_{\mathrm{a}}\right)$ annuli in the septal-lateral plane, (2) peak systolic excursion angles of the posterior $(\alpha)$ and anterior $(\beta)$ leaflets, and (3) depth of leaflet coaptation
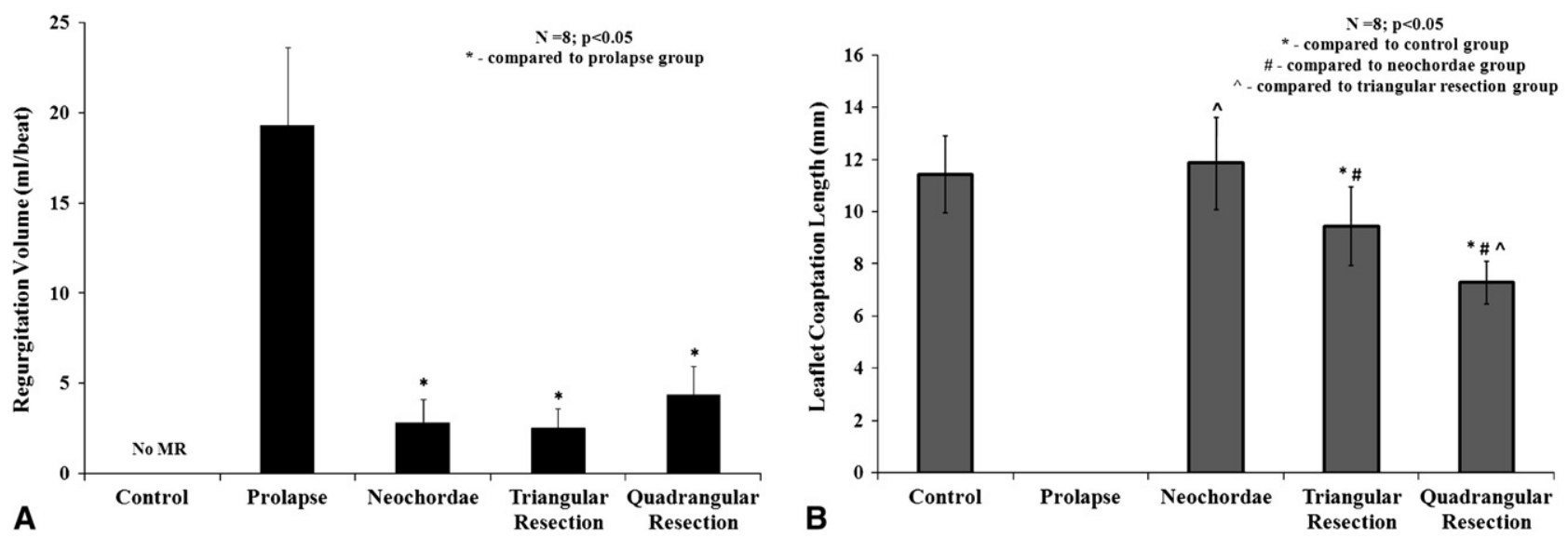

FIGURE 4. A, Variation in regurgitation volume per heart beat for the control, prolapse, and the three repair procedures. B, Variation in peak systolic leaflet coaptation length between the different experimental conditions. 


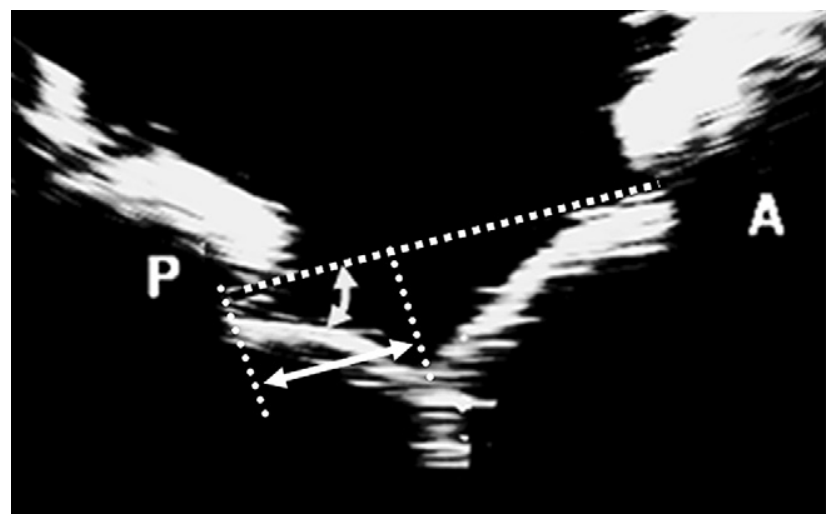

FIGURE 5. Geometric endpoints measured from 2-dimensional echocardiographs to quantify leaflet mobility.

from the mitral annular plane (Figure 5 and Table 1). The distance of the coaptation zone from the anterior and posterior annuli were nearly equal in the control case $\left(\Delta_{\mathrm{p}}=14.2 \pm\right.$ $\left.1.9 \mathrm{~mm}, \Delta_{\mathrm{a}}=20.8 \pm 1.9 \mathrm{~mm}\right)$, showing that the leaflet coaptation was centrally positioned from the anterior and posterior annuli in normal valves. A similar coaptation geometry was observed after neochordoplasty $\left(\Delta_{\mathrm{p}}=15.4 \pm 1.2 \mathrm{~mm}\right.$; $\left.P=.09 ; \Delta_{\mathrm{a}}=20 \pm 2.1 \mathrm{~mm} ; P=.35\right)$ as in the control group. However, both limited triangular resection $\left(\Delta_{\mathrm{p}}=13.1 \pm 1.4\right.$ $\left.\mathrm{mm} ; P=.03 ; \Delta_{\mathrm{a}}=22.2 \pm 2.6 \mathrm{~mm} ; P=.04\right)$ and quadrangular resection $\left(\Delta_{\mathrm{p}}=10.2 \pm 2.0 \mathrm{~mm} ; P=.006 ; \Delta_{\mathrm{a}}=23.9 \pm\right.$ $2.5 \mathrm{~mm} ; P=.01)$ restricted posterior leaflet mobility, resulting in displacement of the coaptation zone posteriorly. Additionally, we quantified the peak systolic leaflet angles made by the posterior and anterior leaflets with the mitral annulus as a measure of systolic leaflet mobility. The posterior leaflet angles in the neochordoplasty group $\left(\alpha=34.2^{\circ} \pm\right.$ $\left.3.6^{\circ} ; P=.77\right)$ and limited triangular resection $(\alpha=$ $\left.37.4^{\circ} \pm 3.3^{\circ} ; P=.25\right)$ were comparable with the angles in the control $\left(\alpha=33.5^{\circ} \pm 6.6^{\circ}\right)$ but significantly higher in the quadrangular resection group $\left(\alpha=51.2^{\circ} \pm 10.8^{\circ} ; P=\right.$ $.01)$, as shown in Figure 5 and Table 1. The anterior leaflet angles were consistent among the four conditions, indicating that the anterior leaflet has a threshold beyond which it cannot move to coapt with the posterior leaflet owing to the limited extension of the anterior chordae tendineae.

\section{DISCUSSION}

In this study, we report a model that simulates the clinical setting of leaflet prolapse resulting from acute chordal rupture, as seen in some cases of endocarditis or fibroelastic deficiency. Two-dimensional and 3-dimensional echocardiographic images obtained from our in vitro model clearly illustrate the segmental P2 prolapse and the anteriorly directed eccentric regurgitation jet (Figure 2, $A$ and $B$ ) after experimental chordal rupture.

Following current trends in mitral valve repair, ${ }^{10}$ three commonly used repair procedures for mitral valve prolapse were selected for this study. Quadrangular resection with annular compression is a standard repair procedure that is associated with good long-term durability ${ }^{11}$ but nonphysiologic mobility of the posterior leaflet after surgery, often resulting in a monocusp valve. Carpentier and associates ${ }^{8}$ proposed quadrangular resection to correct leaflet prolapse in patients primarily with ruptured chordae and excess tissue, wherein removal of the excessive leaflet tissue is useful to reconstruct a normal leaflet segment. Over the years, this technique has evolved into standard practice for correcting posterior leaflet prolapse irrespective of the valve disease, and our study puts additional emphasis on the importance of selecting the appropriate subset of patients with prolapse and distended tissue in whom to use this procedure. Carpentier (as reported by Fornes and associates ${ }^{3}$ ) was the first to recognize that fibroelastic deficient valves may have minimal leaflet distention with acute chordal rupture. Our study shows that in these acutely prolapsing valves, quadrangular resection significantly reduces the posterior leaflet height, thus decreasing the systolic leaflet coaptation length. Mobility of the reconstructed posterior leaflet is often limited owing to rearrangement of the anatomic positions of the chordae tendineae after resection, with the secondary chordae from the P1 and P3 scallops moving toward the center of the posterior leaflet. Such nonphysiologic valve closure could potentially affect long-term repair durability, and our in vitro observations support this potential issue if quadrangular resection is adopted indiscriminately.

Limited triangular resection of the prolapsing posterior leaflet with conservative tissue resection has been reported as a good alternative procedure that significantly reduces the size of the resection and further eliminates the need for annular plication or compression. , $^{12}$ Our findings in nondistended leaflets also suggest improved valve function, in terms of leaflet coaptation and mobility, compared with quadrangular resection. Although the outcomes of triangular resection were better than those with quadrangular resection, a $2-\mathrm{mm}$ reduction in coaptation length and a 2 - to $3-\mathrm{mm}$ posterior displacement of the leaflet coaptation was measured in comparison with the control group. Whether these minor

TABLE 1. Variation in the echocardiographic measures for posterior and anterior leaflet mobility obtained by 2-dimensional echocardiography

\begin{tabular}{lccc}
\hline & Control & Neochordoplasty & Triangular resection \\
\hline Posterior leaflet angle $(\alpha)$ in degrees & $33.5 \pm 6.6$ & $34.2 \pm 3.6$ & $37.4 \pm 3.3$ \\
Anterior leaflet angle $(\beta)$ in degrees & $29.5 \pm 3.6$ & $28.4 \pm 3.9$ & $27.5 \pm 5.4$ \\
\hline
\end{tabular}

*,†Statistical difference compared with the control and other repair groups, respectively. 
differences between triangular resection and controls are clinically significant is not apparent on the basis of our study.

Several groups are now reporting nonresective strategies to preserve leaflet tissue and restore good leaflet coaptation and mobility. ${ }^{6,13,14}$ This study confirms that replacing the ruptured chordae with artificial ePTFE sutures would restore physiologic function of the valve without disturbing the native leaflet structure. Replacing the ruptured chordae with a single ePTFE loop not only eliminated regurgitation as efficiently as the standard resection procedures but also restored leaflet coaptation length to physiologic levels, with excellent mobility of the posterior leaflet.

Neochordoplasty, as performed in this study, seemed to have a benefit over leaflet resection in acute leaflet prolapse without leaflet distention. In this study, two pairs of neochordae equally distributed between the two papillary muscles were used. From each pair of chordae from the same papillary muscle head, one pair supported the free edge of the prolapsing segment and the other supported the segment $1 \mathrm{~cm}$ laterally away from the free edge. Such a chordal distribution was effective in our studies, but it remains unclear whether there is an "optimal" positioning of neochordae, other than to avoid crossing native chordae. We did not use resection with correction of leaflet prolapse by chordal transfer. This represents another alternative surgical strategy that may be beneficial in the setting of minimal leaflet distention.

\section{Limitations}

Any clinical implications of this model must be stated circumspectly. First, this study is an acute case of leaflet prolapse resulting from isolated chordal rupture without any annular or leaflet pathologic change(s). Clearly, we used mitral valves with normal function and tissue properties, which did not take into account any pre-existing patient diseases (eg, bacterial endocarditis) that may affect the choice of mitral valve repair. In the chronic state, myxoid changes in the leaflet tissue and leaflet distention are typically observed and resection procedures have been successfully used in repairing such valves. In this study, the neochordal length was determined with the valve closed, but ideally such an exact measurement is impossible in the clinical setting owing to ventricular motion and movement of the papillary muscles caused by contraction. One other limitation is the use of the same valve preparation for all experimental groups, which dictated the order of repair procedures.

In summary, this study emphasizes the importance of leaflet preservation ${ }^{15-17}$ in repairing leaflet prolapse in otherwise normal leaflet segments. It suggests that either nonresective resuspension of the leaflet margin or limited triangular resection is preferable to quadrangular resection.

We thank Holifield farms of Covington, Georgia, for generously donating the porcine hearts that were used in this study.

\section{References}

1. Carpentier A. Cardiac valve surgery-the "French correction.," J Thorac Cardiovasc Surg. 1983;86:323-37.

2. Anyanwu AC, Adams DH. Etiologic classification of degenerative mitral valve disease: Barlow's disease and fibroelastic deficiency. Semin Thorac Cardiovasc Surg. 2007; 19:90-6.

3. Fornes P, Heudes D, Fuzellier JF, Tixier D, Bruneval P, Carpentier A. Correlation between clinical and histologic patterns of degenerative mitral valve insufficiency: a histomorphometric study of 130 excised segments. Cardiovasc Pathol. 1999;8:81-92.

4. He S, Fontaine AA, Schwammenthal E, Yoganathan AP, Levine RA. Integrated mechanism for functional mitral regurgitation: leaflet restriction versus coapting force: in vitro studies. Circulation. 1997;96:1826-34.

5. Jimenez JH, Liou SW, Padala M, He Z, Sacks M, Gorman RC, et al. A saddleshaped annulus reduces systolic strain on the central region of the mitral valve anterior leaflet. J Thorac Cardiovasc Surg. 2007;134:1562-8.

6. Seeburger J, Kuntze T, Mohr FW. Gore-Tex chordoplasty in degenerative mitral valve repair. Semin Thorac Cardiovasc Surg. 2007;19:111-5.

7. Gazoni LM, Fedoruk LM, Kern JA, Dent JM, Reece TB, Tribble CG, et al. A simplified approach to degenerative disease: triangular resections of the mitral valve. Ann Thorac Surg. 2007;(83):1658-64; discussion 1664-5.

8. Carpentier A, Deloche A, Dauptain J, Soyer R, Blondeau P, Piwnica A, et al. A new reconstructive operation for correction of mitral and tricuspid insufficiency. J Thorac Cardiovasc Surg. 1971;61:1-13.

9. Magne J, Pibarot P, Dagenais F, Hachicha Z, Dumesnil JG, Sénéchal M. Preoperative posterior leaflet angle accurately predicts outcome after restrictive mitral valve annuloplasty for ischemic mitral regurgitation. Circulation. 2007;115: 782-91.

10. Filsoufi F, Carpentier A. Principles of reconstructive surgery in degenerative mitral valve disease. Semin Thorac Cardiovasc Surg. 2007;19:103-10.

11. Gillinov AM. Durability of mitral valve repair for degenerative disease. J Thorac Cardiovasc Surg. 1998;116:734-43.

12. Da Col U, Di Bella I, Bardelli G, Koukoulis G, Ramoni E, Ragni T. Triangular resection and folding of the posterior leaflet for mitral valve repair. J Card Surg. 2006;21:274-6.

13. Salvador L, Mirone S, Bianchini R, Regesta T, Patelli F, Minniti G, et al. A 20year experience with mitral valve repair with artificial chordae in 608 patients. J Thorac Cardiovasc Surg. 2008;135:1280-7.

14. Tabata M, Ghanta RK, Shekar PS, Cohn LH. Early and midterm outcomes of folding valvuloplasty without leaflet resection for myxomatous mitral valve disease. Ann Thorac Surg. 2008;86:1388-90.

15. Dreyfus GD, Corbi P, Rubin S, Aubert S. Posterior leaflet preservation in mitral valve prolapse: a new approach to mitral repair. J Heart Valve Dis. 2006;15:528-30.

16. Perier P, Hohenberger W, Lakew F, Batz G, Urbanski P, Zacher M, et al. Toward a new paradigm for the reconstruction of posterior leaflet prolapse: midterm results of the "respect rather than resect"' approach. Ann Thorac Surg. 2008;86: 718-25.

17. Flameng W, Meuris B, Herijgers P, Herregods MC. Durability of mitral repair in Barlow disease versus fibroelastic deficiency. J Thorac Cardiovasc Surg. 2008; 135:274-82.

\section{Discussion}

Dr Gus J. Vlahakes (Boston, Mass). This study comes from two institutions that have considerable experience with both clinical mitral valve reconstruction surgery and fluid dynamics with respect to the mitral valve and a long history of work in this area. I have a couple of questions that have to do in part with the model and how the model is set up and, second, with potential interpretation.

In the single-frame picture you show of the echocardiogram, the valve apparatus appears to be slightly apically tethered; in other words, the coaptation surface seems to be displaced a little bit further into what would be the ventricle. When you set the apparatus up, how do you determine the initial position of the papillary muscles?

Dr Padala. In 1997 we published a paper in Circulation with Dr Bob Levine in which we looked at echocardiograms to find the relationship between the mitral annular plane and the papillary muscle tips in normal subjects. We used those measurements to set the 
mitral line from the papillary muscle to their normal positions in the simulator as used in that study.

Dr Vlahakes. Second, in the porcine valve, what is the nature of the anatomy of the posterior leaflet? Does it have partial clefts or a scallop?type design that you might see in humans, or is it a continuous sheet of tissue?

Dr Padala. It is a continuous sheet of tissue, but you can see that the P2 is definitely much larger than the P1 and the P3. The anatomy is comparable with that seen in humans.

Dr Vlahakes. One area that I think is potentially missing from the analysis, which may explain some of your findings, is the intervention on the annulus. When you said you introduced some annular compression, exactly what did you mean? Did you change the annular size? Did you change the relationship between the annulus subtending the anterior leaflet versus the posterior leaflet? I think this might potentially have had considerable influence on your ultimate findings.

Dr Padala. We performed annular plication using a compression stitch, keeping the annular size constant.

Dr Alain F. Carpentier (Paris, France). I think this study is very interesting because it does carry on a message that I would like to point out, which is the fact that leaflet tissue should not be resected if there is no excess tissue. There is a misunderstanding in this regard-not in this study, but usually-which is to believe that leaflet resection should be always done. That is my first comment.

My second comment is that there is an alternative to neochordal replacement, that is, chordal transposition. Particularly from the basal chordae, you can transfer them to the margin, which is an easier technique and a more elegant technique using living material. Have you tried this technique?

Dr Padala. Yes. The next study that we are embarking on now is to combine neochordoplasty and chordal translocation and see whether there is a difference between the two. If there is no difference-I am not a surgeon, but surgical chordal translocation may be an easier procedure.

Dr Craig R. Smith (New York, NY). Just so I understand what you actually did, in 8 valves, you did the three repair techniques sequentially in the same valve. Am I right?

Dr Padala. Yes.

Dr Smith. That would seem to me to introduce a bias in favor of the first repair technique.

Dr Padala. It does not really bias toward the first procedure because of the sequence in which we chose the repair procedures. In the first one we did neochordoplasty. In the second one, when we did the triangular resection, the part of the posterior leaflet that had neochordae was removed and encompassed the triangular resection.
Dr Smith. I understand that. It all sounds very neat. It is just hard for me to imagine that it is always quite so neat.

Dr Padala. Okay.

Dr Smith. My second question has to do with Dr Vlahakes' question about the annular compression technique. I am still not clear exactly how that was done. I think many of us would argue that the posterior leaflet looks restricted and coaptation appears limited when you get through doing the reconstruction with a quadrangular resection or a triangular resection. It is frequently not until you put in the ring that coaptation improves. I think it might depend importantly on exactly what you did in that step.

Dr Padala. For the annular compression, when I removed the P2 part of the leaflet, the annulus, which was present at that particular segment, was just plicated outward and sutured onto the silicone annulus that we used in this model.

Dr Smith. I would argue that that is the least effective way to preserve coaptation across the whole length of the posterior leaflet.

Dr Marc R. Moon (St. Louis, Mo). It always seemed important to me to decrease the stress on the posterior leaflet because that is probably what makes the chorda rupture in the first place. The neochordal technique would not relieve that stress. I suspect you would leave them with the same stress?loaded posterior leaflet. How do you feel about that in regard to the need for the annuloplasty, and did you consider doing this without an annuloplasty?

Dr Padala. In this particular study, the silicone annulus that we have made into an annuloplasty ring is actually the annulus. We have not implanted any annuloplasty rings that are commercially available. I guess there are other ways of reducing stress on the chordae and also on the posterior leaflet by probably choosing a different type or shape of annuloplasty ring, but I really cannot comment on that right now because I have not studied that.

Dr Adams. If I can make one final comment about the study, this was not a study trying to differentiate or condemn posterior leaflet resection, which, frankly, has the longest, most credible results in terms of durability, whether you look at freedom from reoperation or recurrence of mitral regurgitation. I think the emphasis is on the specific subgroup in which you have minimal leaflet distention. And, as Dr Carpentier said, there is a misunderstanding that all leaflets should be resected. What we hoped to show in this first study was that that is not the case in the setting of an otherwise normal segment that has acute prolapse.

Craig, I think your points about annuloplasty are well taken. When you start to take out more tissue, clearly the annuloplasty does several things. One of them is stabilizing the repair and removing tension, but it also improves the coaptation lengths. I think you are absolutely right.

I am not sure that was going to affect this particular study very much because the resections were very limited. 